\title{
Three cases of atypical pneumonia caused by Chlamydophila psittaci
}

\author{
Sandy Chau *, Eugene YK Tso, WS Leung, Kitty SC Fung
}

\begin{abstract}
A B S T R A C T
Psittacosis is a zoonotic disease caused by Chlamydophila psittaci. The most common presentation is atypical pneumonia. Three cases of pneumonia of varying severity due to psittacosis are described. All patients had a history of avian contact. The diagnosis was confirmed by molecular detection of Chlamydophila psittaci in respiratory specimens. The cases showed good recovery with doxycycline treatment. Increased awareness of psittacosis can shorten diagnostic delay and improve patient outcomes.
\end{abstract}

\section{Introduction}

Psittacosis is a zoonotic disease caused by Chlamydophila psittaci, an obligate intracellular pathogen belonging to the family Chlamydiaceae. Since its first description in 1879, zoonotic and enzoonotic outbreaks have been reported worldwide. ${ }^{1}$ Transmission occurs through direct contact or inhalation of aerosols from dried faeces, feather dust, or respiratory secretions of infected birds. Individuals with occupational or recreational exposure to birds like bird fanciers and veterinarians are at greatest risk of infection. Person-to-person transmission is rare. $^{2}$ The disease can range from subclinical infection to fatal pneumonia. Here, we report three cases of atypical pneumonia caused by $C$ psittaci in Hong Kong.

\section{Case reports}

\section{Case 1}

A 62-year-old retired male presented in March 2014 with fever, headache, myalgia, cough, and yellowish sputum for 6 days. He had underlying diabetes mellitus, hypertension, gout, and renal impairment. He visited the local bird market frequently and had purchased two parrots before onset of symptoms. The parrots were well all along. On presentation, he was alert and stable and his temperature was $38.4^{\circ} \mathrm{C}$. The oxygen saturation was $96 \%$ on room air. Chest examination revealed left lower zone crepitations. Chest radiograph showed left lower zone consolidation. He was suspected of psittacosis and was treated with ceftriaxone and doxycycline. His sputum was positive for $C$ psittaci by polymerase chain reaction (PCR). Nasopharyngeal swab and
Hong Kong Med J 2015;21:272-5 DOI: $10.12809 / \mathrm{hkmj} 144321$

${ }^{1}$ S Chau *, MB, BS, FHKAM (Pathology)

2 EYK Tso, MB, BS, FHKAM (Medicine)

${ }^{2}$ WS Leung, MB, ChB, FHKAM (Medicine)

${ }^{1}$ KSC Fung, MB, ChB, FHKAM (Pathology)

1 Department of Pathology

2 Department of Medicine and Geriatrics

United Christian Hospital, Kwun Tung, Hong Kong

* Corresponding author: chauky@ha.org.hk sputum were also positive for influenza A virus subtype H3 by PCR. Oseltamivir was commenced. He was afebrile the next day and was discharged after 5 days of hospitalisation. Paired serum collected 12 days apart showed rising Chlamydia group titre from 40 to 80 by complement fixation test (CFT). The parrots could no longer be traced as the patient's son released them.

\section{Case 2}

A 55-year-old male construction site worker with hypertension was admitted in February 2014 with a 1-week history of fever, headache, generalised bone pain, and cough. He had travelled to Shanwei in China and bought a live chicken from a wet market 2 weeks earlier. On examination, his vital signs were stable and had a temperature of $40^{\circ} \mathrm{C}$. The oxygen saturation was $98 \%$ on room air. Chest examination was normal. Chest radiograph showed right upper zone opacities. He was treated as a case of communityacquired pneumonia with amoxicillin-clavulanate, doxycycline, and oseltamivir. Sputum culture showed growth of commensals only. Nasopharyngeal aspirate (NPA) was negative for influenza viruses, Mycoplasma pneumoniae, and Chlamydophila pneumoniae by PCR. Oseltamivir was stopped. His fever subsided on day 3 and he was discharged after 4 days of hospitalisation. Complement fixation test of paired sera taken 2 weeks apart showed a rise in Chlamydia group titre from 20 to 80 . Sputum was retrieved and was positive for $C$ psittaci by PCR.

\section{Case 3}

A 42-year-old female chef was hospitalised in February 2014 with fever, cough, yellowish and 
blood-stained sputum, and breathing difficulty for 1 week. She had no underlying illness. One week prior to her admission, she had travelled to Zhaoqing in China and bought live goose and chicken from a wet market. On admission, she was in respiratory distress and her temperature was $39.2^{\circ} \mathrm{C}$. The oxygen saturation was $90 \%$ on $100 \%$ supplemental oxygen via non-rebreathing mask. Chest examination yielded coarse crepitations over the right side. Chest radiograph revealed right middle and lower zone consolidation, and left patchy haziness (Fig). On the same day, she was transferred to the intensive care unit. She required mechanical ventilation and extracorporeal membrane oxygenation (ECMO). She was treated as a case of severe communityacquired pneumonia with piperacillin-tazobactam, doxycycline, and oseltamivir. Sputum culture showed growth of commensals only. Sputum, NPA, and tracheal aspirate were negative for influenza viruses, $M$ pneumoniae, and $C$ pneumoniae by PCR. Urine was negative for Legionella pneumophila and pneumococcal antigens. She gradually improved and was extubated 3 days later, and ECMO was stopped on day 7. She was discharged on day 24 of hospitalisation. Paired serum drawn 12 days apart showed rising Chlamydia group titre from 80 to 640 by CFT. Polymerase chain reaction for $C$ psittaci was positive in her stored sputum.

The laboratory profiles of the three cases on admission are summarised in the Table.

\section{Discussion}

Psittacosis is an uncommon disease in Hong Kong. Since 2008, this has been made as a statutory notifiable disease. There were 11 confirmed cases and six probable cases reported until 2013. ${ }^{3}$ In 2012, there was an outbreak involving six staff working at the New Territories North Animal Management Centre in Sheung Shui. ${ }^{4}$

Chlamydophila psittaci is classified into nine genotypes (A to F, E/B, M56, WC) based on outer membrane protein A gene sequences, with differential host preference and virulence among the genotypes. ${ }^{1}$ It has been described in at least 460 bird species from 30 orders. ${ }^{5}$ Birds can shed the organisms when apparently healthy or overtly ill. Patient 1 had been exposed to asymptomatic parrots, belonging to the classic culprits, the psittacine birds (parrots, parakeets, budgerigars, cockatiels). Other domestic species-for examples, turkey, pigeon, goose, duck, chicken-can be affected and are often overlooked as potential reservoirs of infection. ${ }^{6}$ In patients 2 and 3, psittacosis was not suspected initially although the patients had been exposed to poultry in China. Chlamydophila psittaci is an emerging pathogen among chicken. ${ }^{7}$ In China, the prevalence of infection among market-sold chickens, ducks, and pigeons has been reported to be $13.32 \%, 38.92 \%$

\section{三宗由殦鴊熱衣原體引起的非典型肺炎病例報告} 周嘉宜、曹育強、梁華盛、馮秀珍

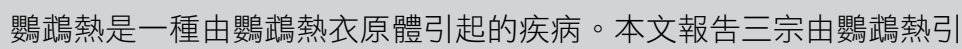
致的不同嚴重程度的非典型肺炎病例。全部個案曾接觸禽鳥, 病人的 呼吸道標本經分子化驗後, 均證實含有䉆武鳥熱衣原體。患者接受鹽酸 多西環素治療後經已康復。若能提高警覺, 可儘早診斷䴗武鳥熱及改善 治療效果。

and $31.09 \%$, respectively. ${ }^{8}$ The substantial zoonotic transmission risk from domestic species should also be recognised.

Psittacosis is a systemic illness that affects several organ systems, and atypical pneumonia as in our cases is the most common manifestation. Patients typically present with influenza-like symptoms, which include high fever, headache, myalgia, and dry cough. Patient 3 complained of blood-stained sputum, which may occur occasionally., ${ }^{1,9}$ The headaches can be so severe as to suggest meningitis on presentation. Diarrhoea is common and can be the chief presenting complaint. Relative bradycardia,

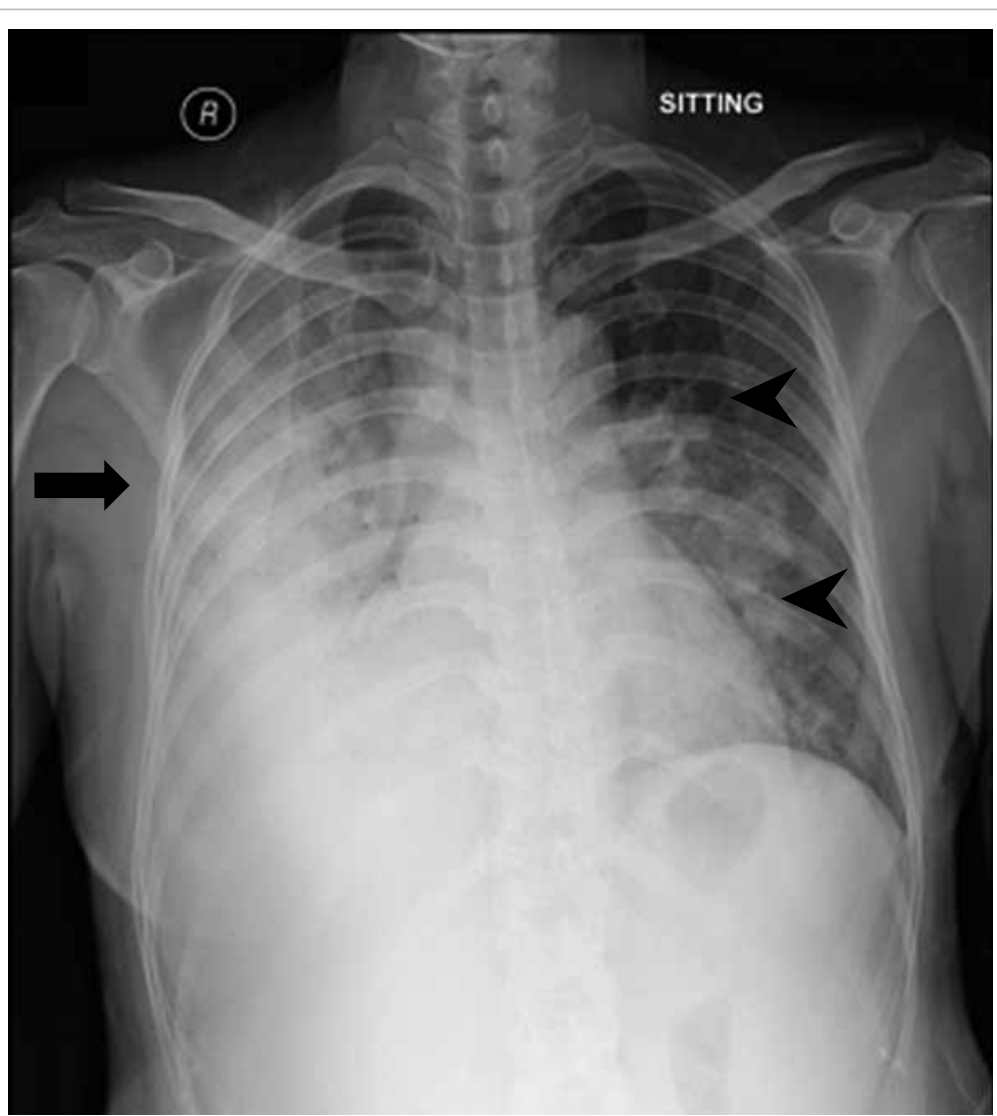

FIG. Chest radiograph on admission shows right middle and lower zone consolidation (arrow), and patchy haziness over left lung (arrowheads) in case 3 
TABLE. Laboratory parameters of our cases on admission

\begin{tabular}{|c|c|c|c|c|}
\hline & Case 1 & Case 2 & Case 3 & Reference range \\
\hline White blood cell count (x 109 /L) & 11.2 & 7.4 & 5.5 & $3.7-9.3$ \\
\hline Haemoglobin (g/L) & 121 & 142 & 89 & $135-173$ \\
\hline Platelet count (x 109 /L) & 353 & 132 & 227 & $160-420$ \\
\hline Sodium (mmol/L) & 135 & 136 & 138 & $136-145$ \\
\hline Creatinine $(\mu \mathrm{mol} / \mathrm{L})$ & 90 & 85 & 72 & $62-106$ \\
\hline Alanine deaminase (IU/L) & 34 & 58 & 54 & $<41$ \\
\hline Aspartate deaminase (IU/L) & 26 & 48 & 109 & $<40$ \\
\hline Alkaline phosphatase (IU/L) & 270 & 92 & 104 & $40-129$ \\
\hline Bilirubin $(\mu \mathrm{mol} / \mathrm{L})$ & 20 & 10 & 6 & $<21$ \\
\hline
\end{tabular}

Horder's spots, and splenomegaly are characteristic physical signs. There may be disparity between the auscultatory findings and radiographic changes of pneumonia. Segmental consolidation in lower lobe is the most common radiographic abnormality although normal chest radiograph has been reported in over $20 \%$ of cases. Hilar lymphadenopathy and pleural effusion are rare. ${ }^{10}$ The white cell count is usually normal or slightly raised, with mildly abnormal liver function. Our case presentations were consistent with psittacosis. However, it is indistinguishable clinically from other causes of atypical pneumonia like $C$ pneumoniae. The severity ranged from mild-to-severe pneumonia requiring intensive care management and ECMO in our cases. Patient 1 had mild illness although co-infected with influenza A. This diversity of presentation is in agreement with other case series. ${ }^{9}$ The mortality rate can be approximately $15 \%$ to $20 \%$ without appropriate treatment but if properly treated, it is rarely fatal. ${ }^{11}$ Extrapulmonary complications such as endocarditis, myocarditis, renal disease, hepatitis, keratoconjunctivitis, arthritis, and encephalitis have also been described.

Chlamydophila psittaci is not covered during routine bacterial or viral workup. Definitive diagnosis can only be established by culture, serology, or PCR specifically targeting on $C$ psittaci. Culture is time-consuming and requires level-3 biosafety facilities. Common serological assays include CFT, enzyme-linked immunosorbent assay, and microimmunofluorescence (MIF) test. The assays are neither sensitive nor specific but MIF test is regarded as more specific. ${ }^{12}$ However, there are still considerable cross-reactions between different species of the Chlamydiaceae family. ${ }^{1}$ Besides, a convalescent serum obtained at least 2 weeks apart is required to demonstrate the 4 -fold rise in titre. In patient 1 , the elevation in CFT titre was not significant and therefore diagnosis may be missed if relying on serology alone. Early use of doxycycline in this patient might have blunted the antibody response. ${ }^{13}$ In patients 2 and 3, serology results were available only retrospectively; PCR for $C$ psittaci was performed subsequently to confirm the diagnosis. In our cases, a nested PCR based on 16S rRNA gene was used. The first-step PCR is genus-specific, followed by the second-step PCR that can detect $C$ psittaci specifically. ${ }^{14}$ This method was demonstrated to be sensitive and specific for detection of $C$ psittaci. When encountering respiratory illness with suspicion of psittacosis, PCR testing on respiratory specimens can offer a rapid and specific diagnosis.

Tetracyclines, in particular doxycycline, are considered to be the treatment of choice. In patients presenting with community-acquired pneumonia, addition of doxycycline to a beta-lactam-based empirical regimen can provide coverage for both psittacosis and other atypical pathogens. Defervescence usually takes place within 48 hours of treatment. Our patients showed significant improvement by day 3 of doxycycline treatment. The commonly recommended duration of treatment is at least 10 to 21 days to prevent relapse. ${ }^{9}$ Macrolides can be used as alternative therapy, but may be less efficacious in severe cases and gestational psittacosis. ${ }^{6}$ Although quinolones have in-vitro activity against $C$ psittaci, their clinical effectiveness remains to be determined. ${ }^{6}$

\section{Conclusion}

Psittacosis often goes unrecognised because of the lack of distinctive symptoms and clinical suspicion. In patients with atypical pneumonia, a history of exposure to birds gives a very valuable diagnostic clue. Early diagnosis with PCR testing and timely initiation of appropriate antibiotics can reduce patient morbidity and mortality.

\section{Acknowledgement}

We thank the Public Health Laboratory Services Branch of the Centre for Health Protection for providing the laboratory testing of psittacosis. 


\section{References}

1. Beeckman DS, Vanrompay DC. Zoonotic Chlamydophila psittaci infections from a clinical perspective. Clin Microbiol Infect 2009;15:11-7.

2. Hughes C, Maharg P, Rosario P, et al. Possible nosocomial transmission of psittacosis. Infect Control Hosp Epidemiol 1997;18:165-8.

3. Statistics on communicable diseases. Available from: http://www.chp.gov.hk/en/notifiable1/10/26/43.html. Accessed 25 Feb 2015.

4. Psittacosis outbreak in an animal management centre, 2012. Communicable Diseases Watch 2013;10:9-10. Available from: http://www.chp.gov.hk/files/pdf/cdw_ compendium_2013.pdf. Accessed 25 Feb 2015.

5. Kaleta EF, Taday EM. Avian host range of Chlamydophila spp. based on isolation, antigen detection and serology. Avian Pathol 2003;32:435-61.

6. Stewardson AJ, Grayson ML. Psittacosis. Infect Dis Clin North Am 2010;24:7-25.

7. Lagae S, Kalmar I, Laroucau K, Vorimore F, Vanrompay D. Emerging Chlamydia psittaci infections in chickens and examination of transmission to humans. J Med Microbiol 2014;63:399-407.

8. Cong W, Huang SY, Zhang XY, et al. Seroprevalence of Chlamydia psittaci infection in market-sold adult chickens, ducks and pigeons in north-western China. J Med Microbiol 2013;62:1211-4.

9. Yung AP, Grayson ML. Psittacosis-a review of 135 cases. Med J Aust 1988;148:228-33.

10. Coutts II, Mackenzie S, White RJ. Clinical and radiographic features of psittacosis infection. Thorax 1985;40:530-2.

11. Smith KA, Campbell CT, Murphy J, Stobierski MG, Tengelsen LA. Compendium of measures to control Chlamydophila psittaci (formerly Chlamydia psittaci) infection among humans (psittacosis) and pet birds (avian chlamydiosis), 2010 National Association of State Public Health Veterinarians (NASPHV). Exotic Pet Med 2011;20:32-45.

12. Petrovay F, Balla E. Two fatal cases of psittacosis caused by Chlamydophila psittaci. J Med Microbiol 2008;57:12968.

13. Heddema ER, van Hannen EJ, Duim B, et al. An outbreak of psittacosis due to Chlamydophila psittaci genotype A in a veterinary teaching hospital. J Med Microbiol 2006;55:1571-5.

14. Messmer TO, Skelton SK, Moroney JF, Daugharty H, Fields BS. Application of a nested, multiplex PCR to psittacosis outbreaks. J Clin Microbiol 1997;35:2043-6. 